\title{
A INSERÇÃO DO TERRÁRIO COMO METODOLOGIA NA DISCIPLINA DE METEOROLOGIA E CLIMATOLOGIA
}

\author{
L. N. MENDES ${ }^{1}$, A. J. S. LOPES ${ }^{2}$, N. C. L. JORGE ${ }^{3}$, A. C. P. ARAÚJO ${ }^{4}$ \\ Instituto Federal de Educação, Ciência e Tecnologia do Rio Grande do Norte \\ luciana.mendes@ifrn.edu.br ${ }^{1}$
}

Artigo submetido em 07/03/2018 e aceito em 14/05/2019

DOI: $10.15628 /$ holos.2019.7057

\section{RESUMO}

Neste trabalho são apresentados os resultados obtidos durante a prática pedagógica utilizando o terrário como ferramenta educacional na disciplina de Meteorologia e Climatologia, em duas turmas do Curso Técnico em Recursos Pesqueiros, modalidade Integrado, no Instituto Federal de Educação, Ciência e Tecnologia do Rio Grande do Norte - Campus Macau. A prática foi adotada como forma de culminância avaliativa da disciplina, cujos objetivos foram despertar nos alunos a revisão e a maior fixação dos assuntos abordados, tais como os fenômenos atmosféricos e suas interações com o meio ambiente, e avaliar, através do relato dos alunos, se a metodologia educacional utilizada foi de fato significativa para a aprendizagem. Outrora, essa metodologia permitiu a participação e inclusão de um aluno surdo durante toda atividade. Para atingir os objetivos propostos, os alunos montaram os terrários e explicaram os fenômenos
\end{abstract}

atmosféricos que ocorreram nestes e a sua interação com os seres vivos. Concluiu-se, com a prática, que o uso de um terrário em sala de aula permite estimular os alunos não só para as práticas da disciplina supracitada, mas também para as questões ambientais, pois, além de demonstrarem ter fixado os conteúdos trabalhados ao longo da disciplina, através das explicações mediadas por eles durante a atividade, alguns ainda fizeram a relação da indisponibilidade de recursos naturais com a degradação ambiental. A proposta ainda serviu para motivar novas práticas educacionais aos alunos da Licenciatura em Biologia do Instituto Federal de Educação, Ciência e Tecnologia do Rio Grande do Norte Campus Macau, que foram avaliadores dos terrários e atuarão futuramente em sala, onde poderão utilizar tal ferramenta.

PALAVRAS-CHAVE: Meteorologia, Terrário Educacional, Educação Ambiental.

\section{THE USE OF TERRARIUMS AS METHODOLOGY TO TEACH THE SUBJECT OF METEOROLOGY AND CLIMATOLOGY}

\begin{abstract}
In this work, we present the results obtained during pedagogical practical lessons using terrariums as an educational tool for the discipline of Meteorology and Climatology, with two classes of students from the Technical Course in Fisheries Resources, at IFRN - Campus Macau. The practical lesson was adopted as a key form of evaluation, and the main goals for using such tool were to inspire the students to revise the contents of the lectures, to help them consolidate the knowledge gathered on subjects such as the atmospheric phenomena and their interactions with the environment, and to assess if the educational methodology in use was significant for the process of learning. This methodology
\end{abstract}

also allowed one deaf student to take part and be included throughout all of the activities proposed. The students set up the terrariums and explained the atmospheric phenomena that occurred within them as well as the interactions of those phenomena with living beings. The use of a terrarium in the classroom enabled students to be stirred, not only by the practical lessons, but also by broader environmental issues. This methodology also motivated the students from the Biology course of IFRN - Campus Macau, who were invited as adjudicators for the terrariums, and plan to use it in their practical lessons in future classrooms as a new educational tool.

KEYWORDS: Meteorology, Educational Terrarium, Environmental Education. 


\section{INTRODUÇÃO}

Atualmente, um dos maiores desafios para os professores é a descoberta de novas metodologias de ensino que sejam prazerosas para os seus alunos e que os estimulem a apresentar interesse nos conteúdos propostos em sala de aula, a fim de garantir uma maior fixação destes. Diante do exposto, o terrário é uma prática muito utilizada tanto para atividades paisagísticas, como também pode ser utilizada para atividades educativas teórico-práticas que permitam viabilizar e/ou conduzir o processo de ensino-aprendizagem.

Os terrários surgiram no final do século XIX, quando o inglês Nathanael Ward, médico e colecionador de plantas raras, aperfeiçoou um recipiente de vidro, que ficou conhecido como "Caixa de Wardian", onde pudesse transportar plantas que descobria em diversas regiões de clima tropical (ROMERO, 2008). Ainda de acordo com este autor, o terrário é definido como um modelo de microssistema, por meio do qual um conjunto de elementos interagem entre si e funcionam juntos como uma totalidade.

Nessa representação de um ecossistema em miniatura, é possível trabalhar o desenvolvimento de plantas e animais nele presentes, as diferentes camadas de substrato utilizadas em sua montagem, bem como outras observações direcionadas a diferentes disciplinas ministradas nas escolas, visto que esta ferramenta proporciona uma versatilidade nos conteúdos que podem ser trabalhados. Dessa forma, ao fazer a montagem do terrário, o aluno considera articular os conhecimentos físicos, químicos e biológicos, e vivencia o processo de criação, troca de ideias e críticas, busca explicações para os fenômenos investigados e apresenta fundamentos e possíveis evidências que os sustentam (BOTELHO, 2008).

Pensando nisso, a professora da disciplina de Meteorologia e Climatologia, de duas turmas do Curso Técnico em Recursos Pesqueiros, modalidade Integrado, do Instituto Federal de Educação, Ciência e Tecnologia do Rio Grande do Norte (IFRN) - Campus Macau, utilizou como forma de culminância avaliativa o uso de terrários, que foram confeccionados pelos próprios alunos para posterior apresentação, cujo objetivo foi despertar nesses discentes a revisão e a maior fixação dos assuntos abordados em sala de aula, tais como os fenômenos atmosféricos e suas interações com o meio ambiente. Dessa forma, os alunos deveriam explicar os fenômenos atmosféricos que estavam acontecendo no recipiente e suas interações sobre os seres vivos.

Levando em consideração a relevância do terrário como ferramenta educacional, alguns graduandos do Curso de Licenciatura em Biologia, ofertado pelo IFRN - Campus Macau, foram convidados para ministrar aulas sobre os materiais indicados para a confecção desse microssistema e sua relação com os seres vivos e com o mundo natural e, posteriormente, para avaliar os terrários feitos pelos alunos do ensino médio, onde poderão utilizar futuramente tal ferramenta em sala de aula. 


\section{REVISÃO BIBLIOGRÁFICA}

Com o intuito de ultrapassar o método de ensino tradicional, fragmentado, que é exposto por muitos autores como descritivo, descontextualizado, "memorístico", pouco reflexivo e que acaba gerando uma barreira de aprendizagem em sala de aula, faz-se necessário que o professor exija de si a capacidade de buscar e utilizar novas metodologias de ensino que se adequem ao campo escolar e aos seus alunos, que vise uma melhora no processo de ensino e aprendizagem e que estimule o interesse dos alunos em sala (LISBOA et al., 2017).

A inserção dessas metodologias no âmbito escolar se faz necessária para a construção de novos aprendizados. Para tanto, os objetivos impostos pelos docentes devem partir do cotidiano do mundo globalizado, o qual influencia os saberes dos indivíduos contemporâneos e possibilita novas descobertas de aprendizagem. Para que isso ocorra, Lisboa et al. $(2017$, p. 2) explicitam que "faz-se necessário o planejamento de atividades que proporcionem e incentive o aluno como um sujeito ativo" e, portanto, quando aplicadas de maneira coerente, os objetivos são alcançados e os resultados são frutos de uma aprendizagem construtivista, visto que o processo de ensino e aprendizagem, com a utilização de uma metodologia diferenciada, estimula os docentes a se interessar e/ou assimilar de fato os conteúdos propostos.

No Projeto Pedagógico do Curso Técnico Integrado em Recursos Pesqueiros (PPC) (IFRN, 2011, p. 20-21), observa-se a importância da utilização de procedimentos didático-pedagógicos diferenciados que possam auxiliar os alunos nas suas construções intelectuais, procedimentais e atitudinais. No documento, consta que, para os critérios de avaliação da aprendizagem, a proposta pedagógica do curso prevê atividades avaliativas que funcionem como instrumentos colaboradores na verificação da aprendizagem, contemplando alguns aspectos, tais como: inclusão de atividades contextualizadas; adoção de procedimentos didático-pedagógicos visando à melhoria contínua da aprendizagem; e discussão, em sala de aula, dos resultados obtidos pelos estudantes nas atividades desenvolvidas.

Com relação aos conhecimentos construídos pelos alunos, na ementa da disciplina de Meteorologia e Climatologia no PPC (IFRN, 2011) consta que os alunos deverão obter:

Conhecimentos sobre os fenômenos atmosféricos e a interação com os seres vivos, através das alterações diárias na previsão do tempo. A relação da dinâmica populacional de animais aquáticos com o regime de chuvas, a umidade relativa do ar, a pressão atmosférica, a temperatura do ar e do solo, a radiação solar, a força dos ventos. $O$ estudo do clima, cujas alterações também ocasionadas pela ação antrópica, tem ocasionado alterações nas correntes marítimas, alterando o clima da Terra. Conhecimento dos estudos meteorológicos, através do uso de estações meteorológicas e seus diferentes instrumentos. (IFRN, 2011, p.)

Nesse sentido, Oliveira et al. (2012) destaca que o estudo da climatologia é de fundamental importância por estar presente no cotidiano dos alunos através dos noticiários e jornais e, dessa forma, deve ser ensinada nas escolas de maneira coerente, e não através do ensino tradicional, fragmentado, descontextualizado e que visa apenas a memorização dos conceitos. 
Para tanto, ao direcionar para os alunos a montagem do terrário de forma a exemplificar um ecossistema em miniatura, a professora não só inclui uma atividade pedagógica visando a melhoria da aprendizagem, mas promove em sala a discussão dos resultados obtidos e consegue trabalhar boa parte dos conhecimentos que os alunos deverão obter ao longo da disciplina. Diante do exposto, Lus (2014) ressalta que utilizar o terrário com o intuito de reproduzir um ecossistema em miniatura diminui a distância entre os conteúdos que geralmente são estudados de forma fragmentada, pois, com essa ferramenta, os alunos podem observar vários fenômenos, tais como: o ciclo da água $\left(\mathrm{H}_{2} \mathrm{O}\right)$, o ciclo do dióxido de carbono $\left(\mathrm{CO}_{2}\right)$, o ciclo do nitrogênio $\left(\mathrm{N}_{2}\right)$, o ciclo de oxigênio $\left(\mathrm{O}_{2}\right)$, o ciclo de nutrientes, as cadeias e teias alimentares, os níveis de organização dos seres vivos e relações ecológicas, a radiação solar, a presença de vapor de água, a umidade, as variações de temperatura máxima e mínima ao longo do dia, entre outras coisas.

Diante da diversidade de conteúdos que podem ser trabalhados, os alunos são capazes de atender alguns objetivos presentes na ementa da disciplina, que são: entender os efeitos da radiação solar na variação da temperatura da atmosfera; e entender o comportamento da evaporação, condensação e precipitação no comportamento climático de uma região (IFRN, 2011). Portanto, com o terrário os alunos podem entender as interações que acontecem nele e relacionálas em conjunto.

Lus (2014) destaca que o terrário também pode ser usado como ferramenta educacional no ensino Ciências, pois, ao estudar o meio ambiente com a utilização dessa ferramenta, podem ser abordados diversos temas ligados à conservação do ambiente, fazendo com que os alunos percebam que qualquer desequilíbrio é capaz de romper com um ecossistema inteiro, o que gera uma sensibilização maior a respeito do assunto abordado. Além disso, eles podem perceber que o ambiente não é composto somente por seres vivos, e sim que é um conjunto onde há a circulação dos materiais, a decomposição e a interdependência entre os seres vivos e os fatores abióticos.

Dessa forma, os licenciandos de Biologia do Campus Macau também poderão utilizar tal ferramenta quando acharem conveniente no ensino de Ciências e de Biologia para despertar o interesse dos alunos pela disciplina, pois, para Santos et al., (2015), os professores ainda usam geralmente o livro didático como único recurso metodológico, o que torna a disciplina cansativa.

Esses autores ainda destacam que existe uma grande dificuldade dos estudantes em associar os conteúdos de Ciências Naturais com o seu dia a dia e, por esse motivo, é importante o professor utilizar metodologias que viabilizem os alunos fazer a associação desses conteúdos com o seu cotidiano para melhorar a compreensão desses. Nesse sentido, Prado (2014) reforça que é necessário repensar a forma como atuar no espaço escolar, usar a criatividade para empreender no ensino a pluralidade das metodologias didáticas, principalmente no ensino de Ciências, disciplina em que se deve ter dinâmica ao usar metodologias de ensino, buscar novidades e ser o diferencial em sala de aula. 


\section{METODOLOGIA}

Este trabalho foi desenvolvido no IFRN - Campus Macau com duas turmas do Curso Técnico Integrado em Recursos Pesqueiros na disciplina de Meteorologia e Climatologia, apresentando uma abordagem qualitativa (PRONADOV \& FREITAS, 2013) que designa o ambiente natural como fonte direta para coleta de dados, interpretação de fenômenos e atribuição de significados.

Para atingir os objetivos propostos, os alunos montaram terrários fechados mediante explicação prévia da professora, bem como dos graduandos do Curso de Licenciatura em Biologia do IFRN - Campus Macau. Após a montagem, os alunos explanaram sobre os fenômenos atmosféricos que ocorreram no terrário e sua interação com os seres vivos.

Para montagem e otimização na construção dos terrários, previamente, os alunos foram divididos em grupos de até seis integrantes; e tiveram cerca de um mês para a pesquisa do material a ser utilizado; a montagem; o cuidado e a observação dos fenômenos que ali estavam acontecendo; e, por fim, a apresentação feita pelos alunos e a avaliação feita pelos licenciandos em Biologia em sala de aula. Os alunos utilizaram os seguintes materiais para a confecção dos terrários: vidros e garrafas PET transparentes, cascalhos, pedrinhas, areia, terra vegetal misturada com adubo, mudas de plantas e papel filme.

\section{RESULTADOS E DISCUSSÕES}

Com os terrários devidamente montados, os alunos os apresentaram (Figura 1) sob avaliação dos Licenciandos em Biologia (Figura 2) e explicaram como se deu o passo a passo da montagem e a importância da efetivação deste para que o terrário pudesse ser de fato comparado a um miniecossistema, além de explanarem acerca dos fenômenos atmosféricos que ocorreram nesse ambiente e sua interação direta com os seres vivos. 


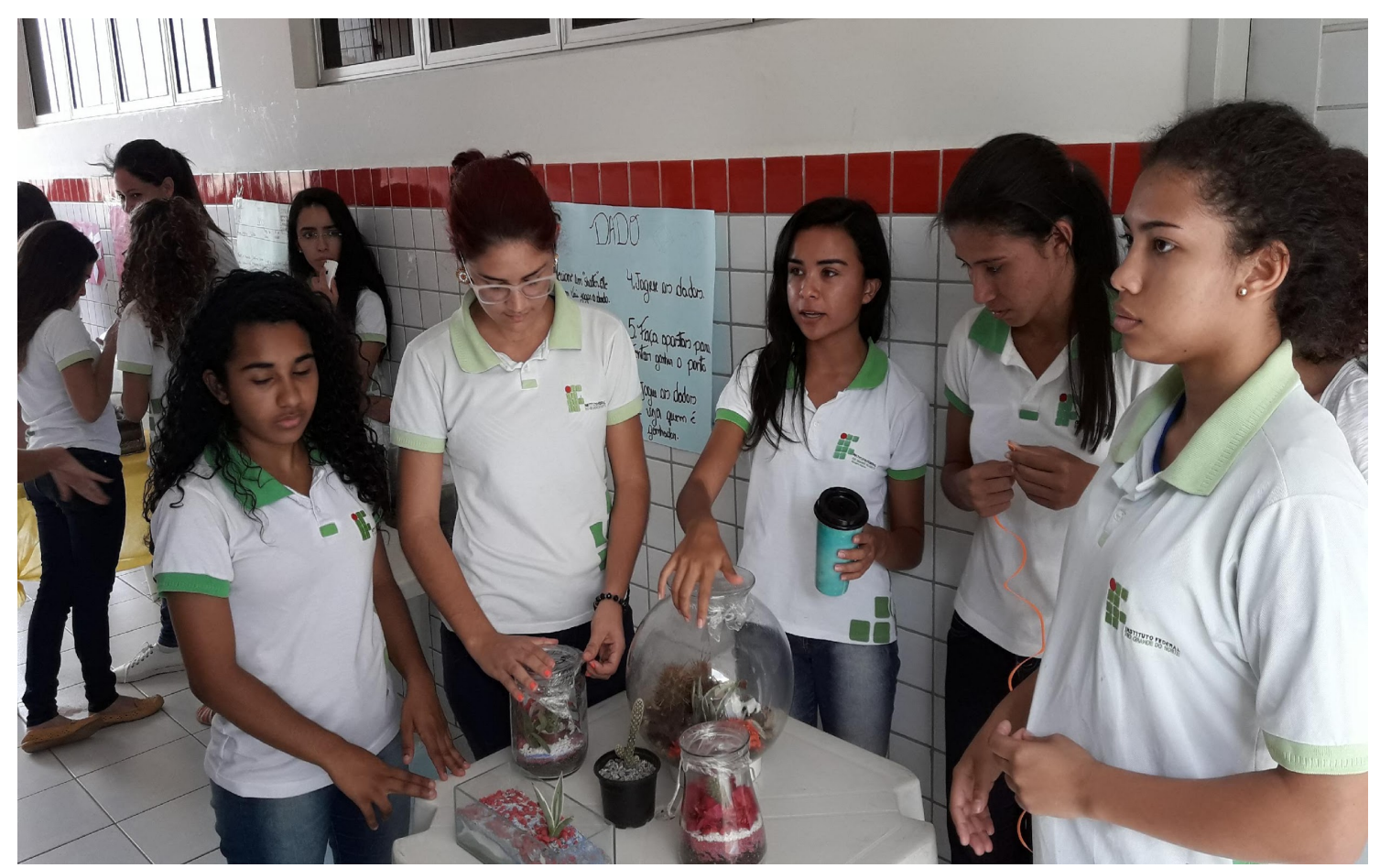

Figura 1: Alunos apresentando os terrários.

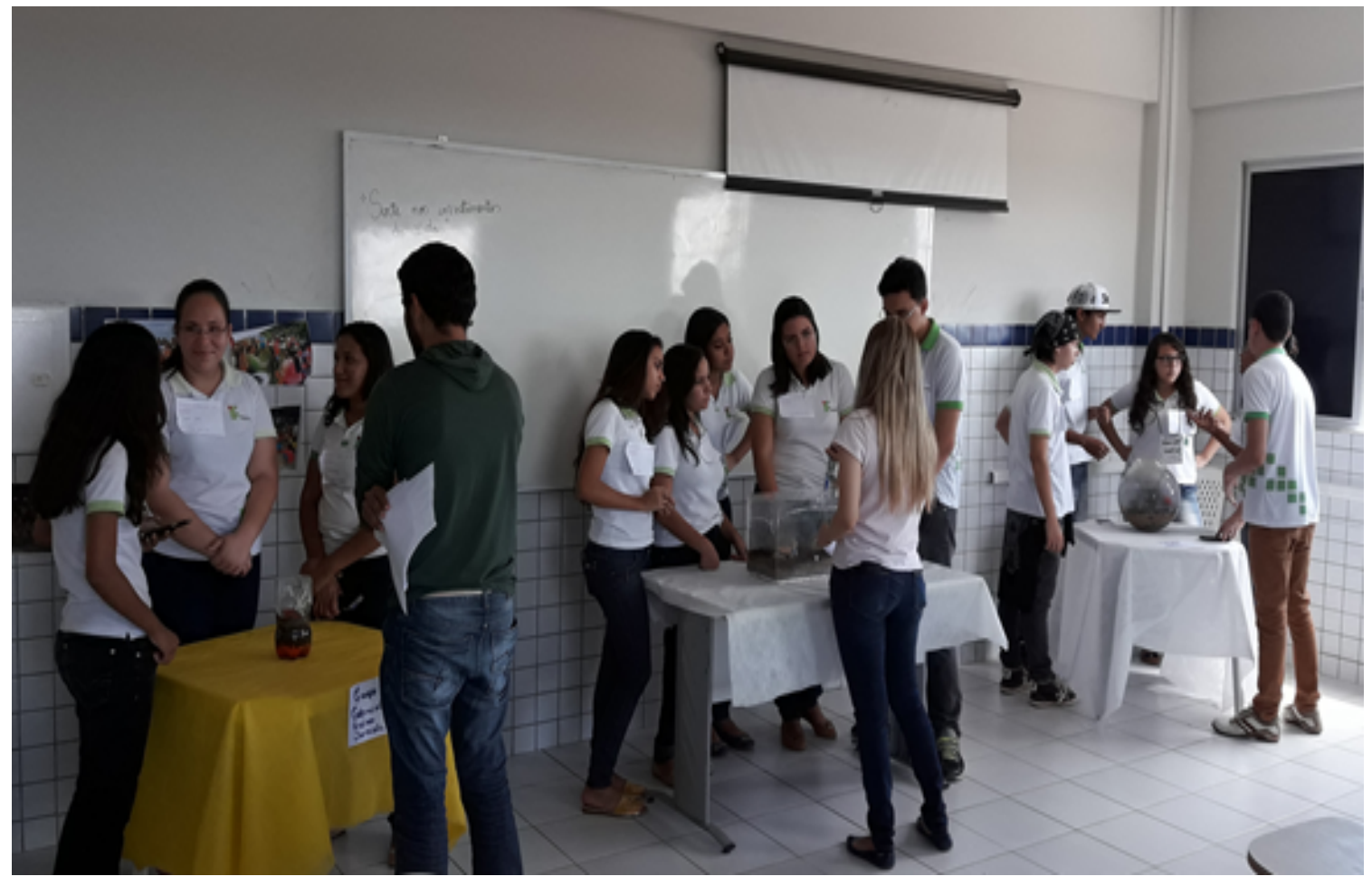

Figura 2: Alunos sendo avaliados por licenciandos em Biologia. 


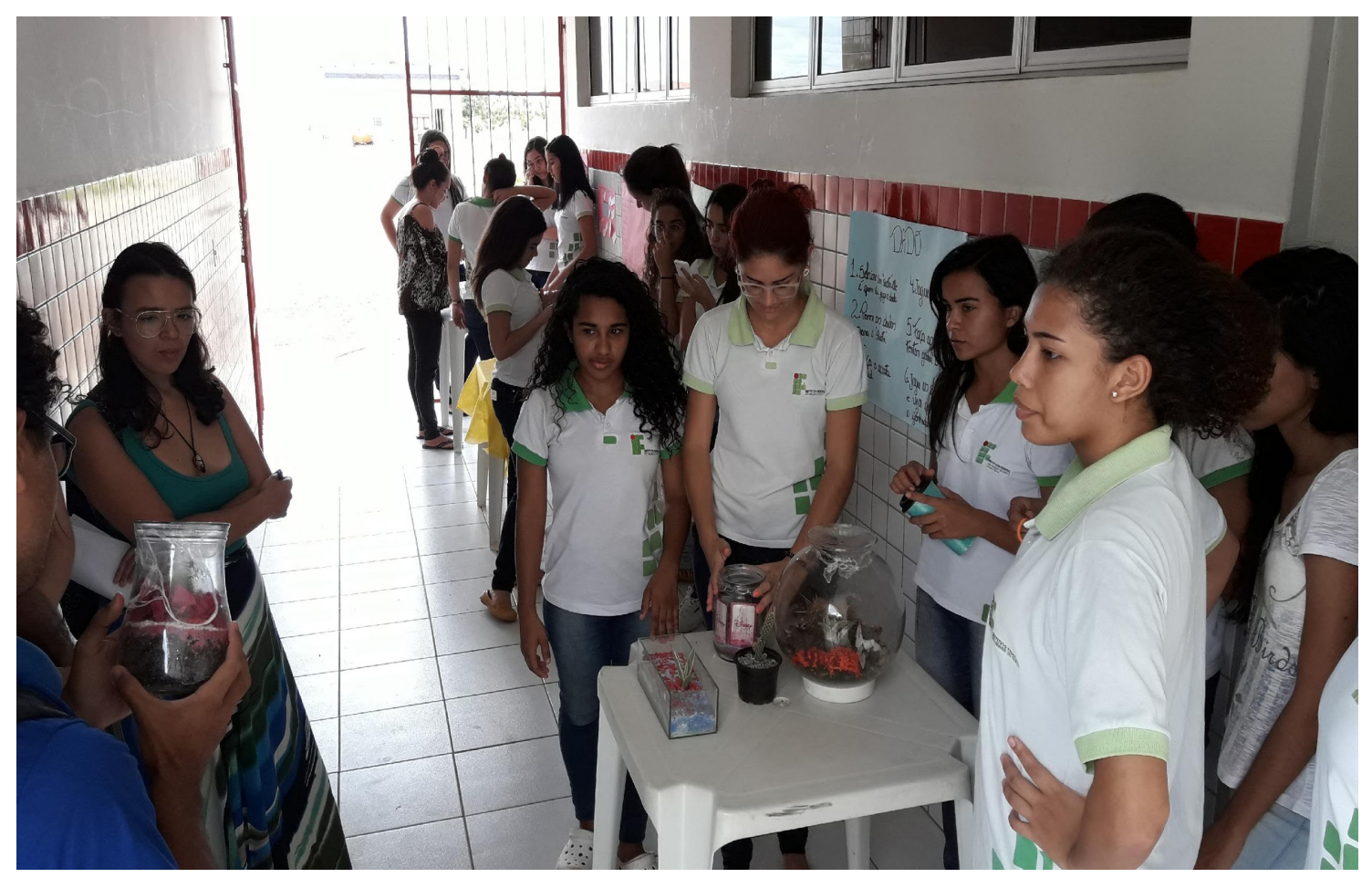

Figura 3: Exposição dos terrários no IFRN - Campus Macau

Durante as aprsentações, os alunos relataram que, para a montagem dos terrários, se fez necessária a escolha de um material transparente para garantir a entrada de luz solar no ambiente e permitir que as plantas pudessem realizar a fotossíntese que é necessária para o seu crescimento, visto que são seres autótrofos e, para isso, foram utilizados vidros e garrafas PET. Dentro desse contexto, Lus (2014) explicita que, na montagem do terrário, os recipientes devem ser totalmente translúcidos para permitir a passagem da luz e o uso de tampas e/ou plástico filme para que ocorra a reciclagem dos nutrientes.

Em seguida, explicitaram que, antes de começar de fato a montagem, foi necessário fazer a limpeza do recipiente com água, sabão e álcool de forma a evitar a alta proliferação de fungos e uma possível perda das mudas de plantas. Feito isso, utilizaram uma primeira camada de pedrinhas e cascalhos, que serviriam para auxiliar na filtração da água, e uma segunda camada de areia com adubo, para servir como fertilizante para as mudas de plantas. Além disso, fecharam o recipiente com tampas ou papel filme simulando a camada de ozônio, de forma a possibilitar a reciclagem dos nutrientes.

Passado a explicação de como se deu a montagem do terrário, os alunos esclareceram os fenômenos atmosféricos acontecidos no terrário e sua relação com os seres vivos. Inicialmente explicaram que borrifaram água somente uma vez e que somente essa primeira regada possibilitou a ocorrência do ciclo da água dentro do recipiente, uma vez que a entrada da radiação solar, permitida pela transparência do vidro e/ou garrafa PET, fez com que o recipiente ficasse aquecido e a água evaporasse. Isso aconteceu porque, após a água atingir seu ponto de ebulição, esta, que estava no solo e no interior da planta, saiu em forma de transpiração pelas folhas da planta e 
evaporou normalmente do solo, condensando-se em forma de gotículas nas paredes do recipiente (Figura 4).

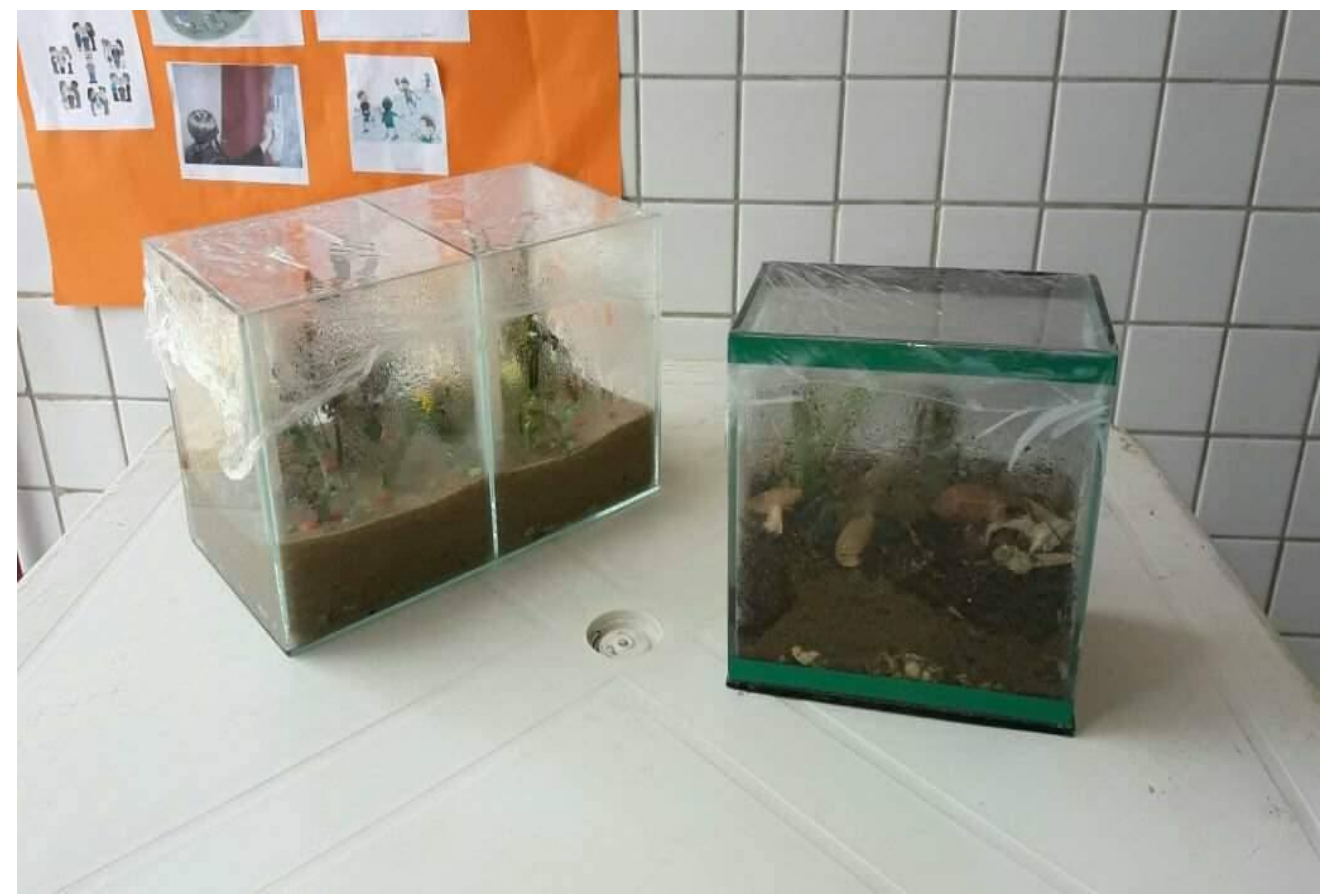

Figura 4: Água condensada nas paredes do terrário.

Tal fato só foi permitido mediante a presença de tampa/papel filme no recipiente, que fez com que a água não fosse perdida pela evaporação para a atmosfera, o mesmo fenômeno representado pela camada de ozônio na terra.

Diante do exposto, os alunos destacaram que o compartilhamento de ideias em todas as etapas do terrário possibilitou sanar todas as indagações feitas nas primeiras aulas até o dia de apresentação. Adiante, as espécies de plantas foram explanadas antes da construção dos terrários, uma vez que a escolha é de suma importância para harmonia e durabilidade do mesmo.

Após a inserção do terrário, foi possível notar que os alunos conseguiram fixar bem os conceitos voltados ao ciclo da água, carbono e os vários elementos trabalhados na disciplina de Meteorologia e Climatologia. Em suma, o instrumento permitiu também a inclusão e participação de um aluno surdo, que, através da língua brasileira de sinais (LIBRAS), explicou, a partir da observação, os resultados do terrário.

Frias apud Festa (2013) ressalta que a inclusão de surdos no ensino regular necessita de uma adaptação do currículo, possibilitando ao aluno metodologias e avaliações adequadas. Nesse sentido, permite uma igualdade entre alunos ouvintes e surdos no processo de ensino e aprendizagem. Vale salientar que a participação e a permanência do aluno surdo em sala de aula estão diretamente ligadas às estratégias de ensino expostas pelo professor. A inclusão é movida pelas transformações entre professor e educando no espaço escolar. 


\section{CONCLUSÃO}

Concluiu-se que o uso de um terrário em sala de aula permite estimular os alunos não só para as práticas da disciplina supracitada, mas também para as questões ambientais, ao entenderem que o desmatamento pode quebrar um dos importantes ciclos, que é o da água, interferindo no processo de fotossíntese da planta, diminuindo a produção de $\mathrm{O}_{2}$ para a atmosfera (troposfera), além de diminuir os reservatórios tanto superficiais, ao alterar o regime de chuvas, e alterar a infiltração de água para os lençóis freáticos. Outrora, notou-se que métodos de ensino aplicado em grupos possibilita maiores resultados na captação e na organização de ideias, de modo que melhora a discussão dos alunos acerca do assunto. Além do mais, a proposta também serviu como uma contribuição para a formação docente e um despertar de novas práticas educacionais para os graduandos da Licenciatura em Biologia do Campus Macau que foram avaliadores dos terrários e experimentaram novas experiências no âmbito educacional, onde atuarão futuramente e poderão utilizar tal ferramenta.

\section{REFERÊNCIAS}

BOTELHO, L. A. (2008). O terrário como instrumento organizador da aprendizagem em ciências da 8a série (9 ano). PARANÁ. Secretária de Estado da Educação. O professor PDE e os desafios da Escola Pública Paranaense. Produção Didático-Pedagógico. Disponível em: <http://www.diaadiaeducacao.pr.gov.br/portals/pde/arquivos/1683-6.pdf>. Acesso em: 13 de dezembro de 2017.

IFRN, INSTITUTO FEDERAL DE EDUCAÇÃO, CIÊNCIA E TECNOLOGIA DO RIO GRANDE DO NORTE. Projeto Pedagógico do Curso Técnico de Nível Médio em Recursos Pesqueiros na forma Integrada Presencial. 2011. Disponível em: $<$ http://portal.ifrn.edu.br/campus/macau/cursos/tecnico-integrado/recursos-pesqueiros1/view>. Acesso em: 18 de novembro de 2017.

Gonçalves, H. B., \& Festa, P. S. V. (2013). Metodologia do professor no ensino de alunos surdos. Ensaios Pedagógicos (Curitiba), 6, 3.

LISBOA, M. D, LIMA, T. C, MENEZES, S. D. S. M. (2017). A IMPORTÂNCIA DE NOVAS PRÁTICAS DE ENSINO NO PROCESSO DE APRENDIZAGEM. In: Encontro Internacional de Formação de Professores e Fórum Permanente de Inovação Educacional, 10(1). Disponível em: $<$ https://eventos.set.edu.br/index.php/enfope/article/view/4705>. Acesso em: 13 de dezembro de 2017.

LUS, S. R. Terrários - Exploração do potencial didático/pedagógico para desenvolver conteúdos ligados aos ecossistemas na disciplina de Ciências para o 6으 ano do Ensino Fundamental. In: Os desafios da Escola Pública Paranaense na perspectiva do professor PDE. Produções Didático Pedagógicas. Mallet, Paraná, 2014. Disponível em: <http://www.diaadiaeducacao.pr.gov.br/portals/cadernospde/pdebusca/producoes pde/20 14/2014 unicentro cien_pdp_sandra_regina_da_lus.pdf $>$. Acesso em: 25 de novembro de 2017. 
MELLO, M. D. (2015). Aprendizagem de climatologia em geografia no ensino médio fundamentada na teoria de Ausubel. Disponível em: <https://repositorio.ufsc.br/xmlui/handle/123456789/157281>. Acesso em: 18 de novembro de 2017.

MORAN, J.M; MASETTO, M.T e BEHRENS, M.A. (2000). Mediação pedagógica e o uso da tecnologia. Novas tecnologias e mediação pedagógica. $14 \underline{a}$ ed. Campinas: Papirus.

OLIVEIRA, D. D, CHAGAS, F. L. R, ALVES, W. S. (2012). Os Desafios De Ensinar A Climatologia Nas Escolas. In li Congresso De Educação-Ueg/Unu-Unidade De Iporá-A Formação De Professores: Uma Proposta De Pesquisa A Partir Da Reflexão Sobre A Prática Docente (pp. 47-51). Disponível em: <http://www.cdn.ueg.br/arquivos/ipora/conteudoN/974/CE_2012 09.pdf>. Acesso em: 18 de novembro de 2017.

PRADO, K. (2014). Metodologias didáticas no ensino de ciências do município de Céu Azul-PR. Disponível em: $<$ http://repositorio.roca.utfpr.edu.br/jspui/bitstream/1/3510/1/MD_ENSCIE_IV_2014 54.pd f> Acesso em: 27 de novembro de 2017.

PRODANOV, C. C, FREITAS, E. C. (2013). Metodologia do trabalho científico: métodos e técnicas da pesquisa e do trabalho acadêmico-2 ${ }^{a}$ Edição. Editora Feevale. Disponível em: $<$ http://www.feevale.br/Comum/midias/8807f05a 14d0-4d5b-b1ad-1538f3aef538/E book\%20Metodologia\%20do\%20Trabalho\%20Cientifico.pdf>. Acesso em: 18 de novembro de 2017.

ROMERO, P. G. Terrário: metodologiada diferenciada em Ensino de ecologia. $29 \mathrm{f}$. Trabalho de Conclusão de Curso - Curso de Ciências Biológicas, Centro Universitário La Salle, Canoas, 2008. Disponível em: $<$ https://biblioteca.unilasalle.edu.br/docs online/tcc/graduacao/ciencias biologicas licencia tura/Para\%20catalogar/2008-1/LIC\%203.pdf>. Acesso em: 18 de novembro de 2017.

SANTOS, C. D. J. S, DOS SANTOS BRASILEIRO, S. G., MACIEL, C. M. L. A, DE SOUZA, R. D. (2015). Ensino de Ciências: Novas abordagens metodológicas para o ensino fundamental. Revista Monografias Ambientais, 14, 217-227. Disponível em: $<$ https://periodicos.ufsm.br/remoa/article/viewFile/20458/pdf $>$. Acesso em: 27 de novembro de 2017. 